\title{
Affordability of battery electric vehicles based on disposable income and the impact on provincial residential electricity requirements in South Africa
}

\author{
N.S. Pillay ${ }^{\mathrm{a}, \mathrm{b},{ }^{*}, \text { A.C. Brent }}{ }^{\mathrm{c}, \mathrm{d}}$, J.K. Musango ${ }^{\mathrm{e}}$ \\ a Department of Industrial Engineering, Stellenbosch University, Private Bag X1, Matieland, 7602, South Africa \\ ${ }^{\mathrm{b}}$ Eskom SOC, Research Testing \& Development, Private Bag 40175, Cleveland, 2022, South Africa \\ ${ }^{\mathrm{c}}$ Department of Industrial Engineering, and the Centre for Renewable and Sustainable Energy Studies, Stellenbosch University, Private Bag X1, Matieland, \\ 7602, South Africa \\ d Sustainable Energy Systems, Engineering and Computer Science, Victoria University of Wellington, Kelburn, Wellington, 6140, New Zealand \\ e School of Public Leadership, and the Centre for Renewable and Sustainable Energy Studies, Stellenbosch University, Private Bag X1, Matieland, 7602, South \\ Africa
}

\section{A R T I C L E I N F O}

\section{Article history:}

Received 22 May 2018

Received in revised form

22 October 2018

Accepted 24 October 2018

Available online 17 November 2018

\section{Keywords:}

Battery electric vehicles

Electricity demand

Carbon emissions

South Africa

\begin{abstract}
A B S T R A C T
South Africa's political history, unique demographic profile, and economic growth drivers, present a challenge in adopting universal strategies and business models to plan for the impact of battery electric vehicles in the residential sector. This paper investigated battery electric vehicle (BEV) substitution of internal combustion engine vehicles (ICEVs) on a provincial level, to better plan for additional electricity requirements. This was achieved by developing the E-StratBEV model, using system dynamics. The model results show that nationally, although the Low Growth scenario indicates about 233,700 BEVs by 2040 , the adjusted number (based on the spending behaviour within deciles) may result in 44,155 BEVs while the High Growth scenario's expected 2.39 million BEVs by 2040 could be adjusted down to 451,736 BEVs. For a coal heavy supply mix, the cumulative carbon emissions from 2019 until 2040 resulted in negligible benefits, so provinces may not be able to leverage on passenger electric vehicles to reduce provincial environmental emissions. Lastly, the BEV growth drivers introduced an additional $1589 \mathrm{BEVs}$ to the Low Growth scenario and an additional 16,257 BEVs to the High Growth targets from 2019 to 2040, with the purchase price being the dominant driver.
\end{abstract}

(c) 2018 Published by Elsevier Ltd.

\section{Introduction}

South Africa's energy intensity is met largely by fossil fuel generation options [1,2]. Projections of energy demand in the transport industry, based on current vehicle growth trends, indicate a potential doubling of $\mathrm{CO}_{2}$ emissions by 2050 [3], which warrants an urgent need for roll-out plans to reduce greenhouse emissions and energy consumption, and to protect the environment; considering that the transport sector accounted for about $13 \%$ of national greenhouse gases in 2012 [4]. Due to the need to reduce its carbon emissions, South Africa compiled the Green

\footnotetext{
* Corresponding author. Department of Industrial Engineering, Stellenbosch University, Private Bag X1, Matieland, 7602, South Africa.

E-mail addresses: pillayna@eskom.co.za (N.S. Pillay), acb@sun.ac.za (A.C. Brent), jmusango@sun.ac.za (J.K. Musango).
}

Transport Strategy in 2016, with a focus on the promotion of green transport technologies, including the uptake of the electric vehicle (EV) and hybrid electric vehicle technologies [5].

Increasing volumes of EVs mean that electricity utilities, such as Eskom SOC (a State Owned Company), with a coal-dominated base [2] will have to consider the environmental impacts with the additional demand that would be expected from EV electricity charging requirements. The penetration rate of Battery Electric Vehicles (BEVs) will vary depending on factors, such as: consumer acceptance, government support in the form of subsidies for localised manufacturers and the consumer, changes to vehicle import taxes, range anxiety due to limited battery ranges, charging infrastructure, and retail BEV costs [6]. Additionally, Zubaryeva et al. [7] suggests driving factors, such as transport criteria (i.e. targeting consumers with multiple car requirements), and demographic criteria (linking income to EV adoption). Venter and Mohammed [8]; in developing a multinomial logit model of vehicle 
ownership, indicate that household income and the number of workers per household had a strong positive relationship to vehicle ownership.

In South Africa, the economic activities and affordability propensities, as a function of disposable income, is influenced by country-specific challenges, such as: high inflation rates, which increased from $4.6 \%$ in 2015 to $6.4 \%$ in 2016, high public debt (about $50 \%$ of GDP), lack of competition due to high business costs, and political uncertainty [9]. These country-specific challenges impacting income distribution, disposable income, and ultimately the affordability of luxury goods such as BEVs, required a model to assist with incorporating the complexities associated with BEV market penetration forecasts, specific to the regional variations within the country; a knowledge gap that led to this study.

This paper presents the results from the development of one such model, known as E-StratBEV (Electricity Strategy Battery Electric Vehicle) simulator, to understand the relationship between affordability of passenger BEVs (based on the average disposable income of consumers in the residential sector), against a backdrop of various key drivers (retail price, charging infrastructure, reputation effect and range anxiety), not just on a national level, but provincially in South Africa. The nine Constitutional provinces of South Africa included in this study were: Mpumalanga; Limpopo; Gauteng; North West; Northern Cape; Free State; KwaZulu Natal; Eastern Cape; and Western Cape.

\section{Contextualising BEV forecasts in South Africa}

Since 2012, a plethora of events, initiatives and rollouts to support the introduction of EV technology emerged in South Africa, including: the EV industry roadmap for South Africa in 2013, alongside the launch of the green fleet by the Department of Environmental Affairs [10]; the formation of the Electric Vehicle Infrastructure Alliance (EVIA) with the purpose of developing EV infrastructure hardware and software standards, including the rollout of charging stations at appropriate locations; and an EskomNissan BEV program to pilot ten passenger sedans in 2013 [11]. With these initiatives to support the substitution of the internal combustion engine (ICE) vehicle with EVs, market penetration forecasts emerged.

Work carried out by GIZ [12]; on behalf of the Department of Transport in South Africa, investigated the relationship between the demand for transport and societal prosperity within the country using the Living Standards Measure (LSM). The results indicated that a steady increase in household consumption is directly proportional to the increase in the demand for transport. Additionally, supporting the growth of EVs would require revising import taxes, provision of EV manufacturing trade incentives, manufacture of EV batteries cost-efficiently, and set annual targets for EV penetration in the government fleet.

For this study, a Low Growth and a High growth BEV target was chosen to run scenarios from 2019 until 2040. The High Growth BEV target was based on the Government's Green Transport Strategy, published by Department of Transport, which plans for 3 million electric vehicles by 2050 [5]. Using an S-curve to find the value at year 2040, this would equate to a target of 2.39 million EVs by 2040.

The Low Growth scenario used the GDP parametric since an increase in luxury goods purchases (such as electric vehicles) appears to correlate positively with an improvement in economic conditions within a country [13]. South Africa's GDP is on average 0.0057 of the world's GDP, which means a target of 233,700 BEVs by 2040 for South Africa, using the Bloomberg New Energy Finance forecast 41 million global electric vehicle sales by 2040 (about 35\% of new light duty vehicle sales) [14]. This study used E-StratBEV to determine the provincial and national affordability of $\mathrm{BEV}$ purchases using average disposable income profiles, and the BEV targets shown in Table 6 . The results from the study can be used to plan future charging infrastructure, prevent shortfalls or overinvestment in electricity generation capacity in the country and understand the trade-offs in carbon emissions in the transport and electricity sectors.

\section{The E-StratBEV model}

Various modelling approaches for studies on EVs were evaluated, including: agent-based models [15], consumer choice models [16], stochastic models and Markov modelling [17], EU-TIMESbased modelling [18], general algebraic modelling [19], and system dynamics [20].

The system dynamics method chosen for the E-StratBEV development allowed for the understanding of the driving forces that impact the market penetration rates of electric vehicles in a non-linear fashion, while taking feedback loops into account. Although the BEV targets (Table 6), identified in Section 2, were used to generate scenarios, the E-StratBEV simulator timeframe ended in 2050 to align with South Africa's latest Integrated Resource Plan [1], with BEV market penetration extending from 2019 until 2040.

Empirical data (e.g. BEV charging and electricity consumption profiles, distances travelled etc.) was obtained from the Eskom three-year BEV study [21].

In setting up the stock-flow-feedback structures in the submodules in the E-StratBEV, there had to be alignment with patterns of behaviour that are consistent with long-term change, taking into cognizance the fact that complex systems are dynamic and most often non-linear if causal relationships and feedback mechanisms are to be considered [22]. This study utilised the logistics curve equation specified in Meyer [23]; shown in Equation (1), which allows for asymptotic conversion to lower values, by specifying a negative value for $U_{1}$, or a positive stabilizing non-zero value by retaining a positive value for $U_{1}$.

$$
P(t)=U_{0}+\frac{U_{1}}{1+\exp \left[-c\left(t-t_{0}\right)\right]}
$$

where $P$ is the dependent variable and $P(t)$ is a function of time $t ; U_{0}$ is the zero offset; $U_{1}$ is the ultimate increase (or decrease) above $U_{0}$, modelled using a S-curve; $c$ is a growth rate exponent that determines the maximum slope of the S-curve; and $t_{0}$ is the time at which the maximum slope is reached (inflection point). iSee Stella software was used for to develop of the four main modules of the EStratBEV, which included sub-modules shown in Table 1.

\subsection{Electricity generation capacity module}

The generation capacity module calculated the energy sent out $(\mathrm{MWh})$ based on the current and planned generation mix. The power generation options in the supply module included 37,913\&\#x202F;MW of coal power plant capacity, besides other generating capacities in the power utilities mix (such as 1860\&\#x202F;MW nuclear, 2732\&\#x202F;MW hydro-pumped storage, 2243\&\#x202F;MW gas cycle turbines, and 771\&\#x202F;MW of hydro-electric power) [2]. Individual power stations differ in performance attributes, auxiliary power consumption, and net energy produced, hence the overall performance measures and total electricity generated were determined using weighted average performance formulas [3], shown in Equation (2). 
Table 1

Modules and sub-modules in E-StratBEV.

\begin{tabular}{|c|c|}
\hline Module & Sub-module \\
\hline $\begin{array}{l}\text { 3.1 Electricity } \\
\text { Generation Capacity }\end{array}$ & $\begin{array}{l}\text { - Installed capacity with performance factors } \\
\text { - Energy sent out } \\
\text { - } \mathrm{CO}_{2} \text { emissions in using baseload coal-fired stations }\end{array}$ \\
\hline 3.2 Economy & $\begin{array}{l}\text { - Gross Domestic Product (GDP) } \\
\text { - Residential electricity consumption }\end{array}$ \\
\hline $\begin{array}{l}3.3 \text { Income and Vehicle } \\
\text { Affordability }\end{array}$ & $\begin{array}{l}\text { - Disposable income (per decile and per province) } \\
\text { - Internal Combustion Engine Vehicles (Actual based } \\
\text { on registrations; and Affordable based on } \\
\text { disposable income) per decile and per province }\end{array}$ \\
\hline 3.4 BEVs & $\begin{array}{l}\text { - Electrical energy consumption } \\
\text { - Transport sector emissions } \\
\text { - Linkage to range anxiety, reputation effect, } \\
\text { charging stations and retail price (includes import } \\
\text { taxes and battery costs) }\end{array}$ \\
\hline
\end{tabular}

$M=\frac{\sum m_{i} C_{i}}{\sum C_{i}}$

where $i$ is the power station, $M$ is the power station's capacity weighted average of performance measure $m ; m_{i}$ is the performance measure for the power station (e.g. load factor); and $C_{i}$ is the capacity of station, $i$.

The time series performance factors, such as planned and unplanned outage allocations, as well as the stations auxiliary consumption, were used to calculate the energy sent out. The energy sent out was then used to determine the $\mathrm{CO}_{2}$ emissions. An emission factor of electricity generation process of $924.4 \& \# \times 202 \mathrm{~F} ; \mathrm{kg}$ per MWh [24] was used, assuming the additional electricity demand required for BEV charging would be met from coal-fired baseload power stations.

\subsection{Economy module}

The economy module is made up of the GDP sub-module and the residential electricity demand sub-module.

\subsubsection{GDP sub-module}

The Real Economy Bulletin, published in 2016 [25], indicates that the Gauteng province accounts for over a third of the GDP, and almost a quarter of the population, in South Africa, whilst the Eastern Cape province population fraction is $13 \%$ with an $8 \%$ share of GDP. Thus, there are vast differences in the economies and GDP per capita on a regional scale in the country, and this had to be considered in the model structure for GDP projections.

Previous research by Nel [26] included causally linking the national GDP to the residential consumption using a system dynamics model, whereby the GDP was not disaggregated on a provincial level and based on 2005 base year calculations, using purchasing power parity (PPP). PPP is used since it provides a better comparison of real GDP compared to market exchange rates (considers constant value for a "basket" of goods and services). This study involved using the same causal equation to link residential consumption with GDP but using an updated, modified GDP submodule structure with base year 2010 (this aligns with the national and European changes implemented in February 2013, which re-referenced short term statistics and time series data from base year 2005-2010) [27,28].

The GDP sub-module (Fig. 1) allows the simulation run of annual changes in electricity residential consumption based on a GDP target expected over time. The target GDP was set at a $2 \%$ constant annual growth based on South Africa's National Treasury Budget

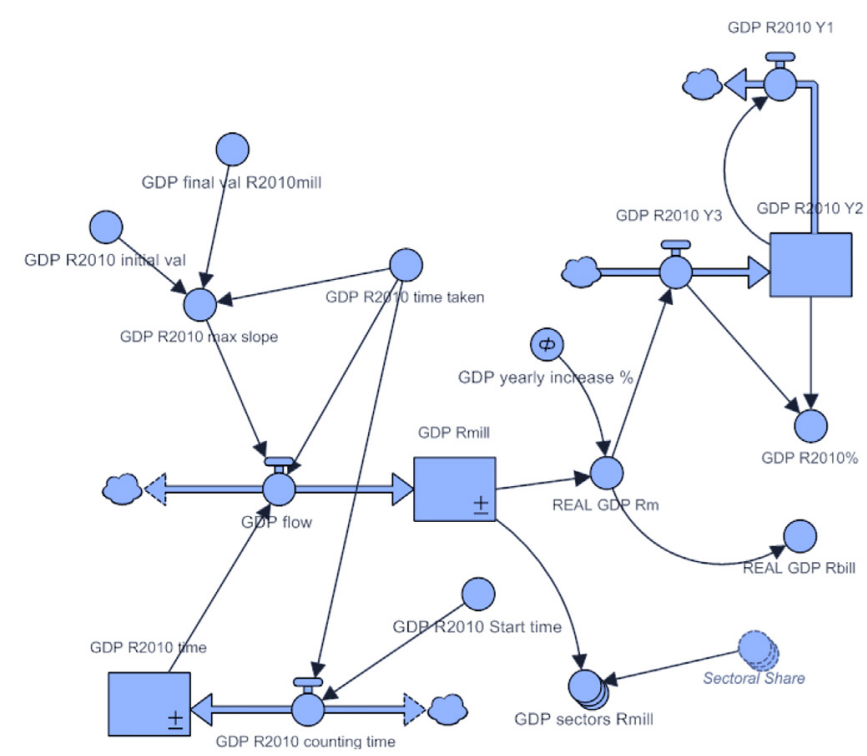

Fig. 1. GDP sub-module.

Review [29], from 2018 until 2050 (the end of the simulator timeframe).

The inflow to the national GDP stock included historical GDP data until 2017, and then projected future growth using Equation (1). After calculating the national GDP using 2010 as a base year, the GDP per capita was calculated by dividing the GDP stock by the population stock (with a similar model structure to the GDP submodule using Equation (1)).

\subsubsection{Residential electricity consumption sub-module}

Depending on the economic growth profiles in the provinces, as well as the disposable income of these residential sectors, passenger motor vehicle ownership volumes are different. The substitution of the ICE vehicles with BEVs would mean greater demand and hence consumption of electricity, and by understanding which province is most likely to require more electrical energy to charge the BEVs, it may be possible to plan charging infrastructure and ensure adequate electricity supply. With the Business-as-usual (no BEV market penetration) scenario, Limpopo, Mpumalanga and the Northern Cape provinces have extremely high electricity usage (91\%, 89\% and 98\% respectively), followed by candle and firewood energy sources [30]. In the Mpumalanga province, coal as an energy source is the highest relative to all the other provinces $(26 \%)$. Electrical energy is a dominant source of energy in the Gauteng (89\%) and the Western Cape (99\%) provinces.

The residential consumption ${ }^{1}$ sub-module was developed to determine the provincial electricity consumption and then to determine the additional electricity consumption requirements based on the BEV targets (Table 6).

The Final Consumption Expenditure ${ }^{2}$ (FCE) as a fraction of GDP was calculated based on original work by Nel [26]; as an input into Equation (3) to calculate the residential electricity consumption $(E)$.

\footnotetext{
1 Electrical power is expressed in megawatts (MW) and reflects the output from the power stations while the energy consumed from electricity generation is measured megawatt-hours (MWh). The total residential electricity consumption in MWh was summed over the simulation timeframe (1993-2050).

2 Final Consumption Expenditure is expenditure by households linked to good
} and services used to satisfy wants and needs. 
$\log (E(F C E))=\log \left(U_{0}+\frac{U_{1}}{1+\exp \left[-c\left(F C E-F C E_{0}\right)\right]}\right)$

where $E$ is the electricity consumption per capita per year and FCE is the Final Consumption Expenditure per capita per year, $U_{o}$ is the initial household electricity consumption per capita per year, and $U_{1}$ is the expected final electricity consumption for the end of the simulation timeframe (2050). The residential consumption was then calculated, linked to historical GDP data until year 2016, and then a constant future growth GDP of $2 \%$ until year 2050. This residential consumption (no BEV penetration and a 2\% GDP growth) was used as a baseline residential electricity consumption trend.

\subsection{Income and vehicle affordability module}

The Motor Industry Development Program (MIDP) was formed in South Africa in 1995 with a goal to transform the automotive industry, and through motor industry policies, supported an increase in vehicle sales [31]. Besides these policy initiatives, other factors, such as the income effect, also contributed to the increase in sales. The income effect occurs when consumer's propensity to purchase and enter a market increases, due to changes in income [32].

An econometric car ownership model shows a long-term relationship between per capita car ownership and per capita income as following a Gompertz curve (similar to the logistic S-curve, but with a slower rate of saturation) [33]. Fouquet (2012) indicates that income and price elasticities of passenger transport demand will decline over time, more rapidly in developing economies as opposed to developed economies. Venter and Mohammed [8] developed a multinomial logit model of vehicle ownership, which indicates that household income and the number of workers per household had a strong positive relationship to vehicle ownership, with high-income households making vehicle purchase decisions irrespective of the number of dependents in the household. Later studies, by Guerra [34]; indicate that if a household's income were to double then the household was $44 \%$ more likely to get an additional car. Based on this literature, sub-modules were developed for the provincial disposable income in South Africa. The disposable income was then linked to the ICE vehicle sub-module.

\subsubsection{Disposable income sub-module}

Disposable income is when an individual's income after personal income tax has been deducted, and includes labour remuneration, income from property, government transfers and incorporated business enterprise transfers [35]. The highest annual average disposable income (2013 data) is in Gauteng (R727 585), Kwazulu-Natal (R322 013) and the Western Cape (R317 065), while the lowest annual average disposable income was in Limpopo (R127 256), the Free State (R96 719) and the Northern Cape (R39 $897)$, in the same year [36].

For the disposable income sub-module (at 2010 base year), the real disposable income time series data from 1995 until 2016 [37] was used to model the future trend using the logistic Equation (1). It was necessary to calculate the real disposable income on a national level first and then the number of households per province was used to calculate the real disposable income on a provincial level.

\subsubsection{ICEV sub-module (Actual and Affordable vehicles)}

This study used historical passenger motor vehicle data in the residential sector from the year 1995 until 2017 [38] to model the future growth using logistic Equation (1). A sub-module was developed for the ICEVs, with a stock for the "Actual" number of ICEVs and a stock linked to a model structure that calculated the "Affordable" number of ICEVs. Regression equations were used to derive the trends until 2050, with $x$ the time steps and $y$ the actual number of ICEVs (Table 2).

The IRR average monthly income per proportion of households with a motor vehicle [39] (Table 3) was used to build the Affordable ICEV sub-module using conditional statements, on a national level.

An income decile shows the average income for different income groupings in society (a decile splits the households into 10 equal parts with decile 1 representing the lowest income and decile 10 the highest income). The number of Actual and Affordable motor vehicles per income decile (nationally) was also calculated using the transport vehicle purchase expenditure fractions in Table 4 [41], to understand which deciles are more likely to purchase new vehicles and which deciles live beyond their financial means, namely: Actual greater than Affordable number of motor vehicles.

\subsection{BEVs}

\subsubsection{BEV demand}

For the E-StratBEV scenarios (Table 7), using the BEVs targets in Table 6, the ICEVs were substituted with BEVs in each province. The BEV electricity demand was calculated (Equation (4)) where Power Consumption equalled 21.25\&\#x202F;kWh per 100\&\#x202F;km (this is bound to change with technology improvements, but was used in the simulator as a constant based on empirical data from the Eskom-Nissan EV pilot study) [11].

\section{$B E V$ electricity demand $=$ Distance $\times$ Power Consumption $_{B E V}$

$$
\times \text { No of BEVs province }
$$

\subsubsection{Transport sector emissions}

The additional BEV demand (with various BEV targets in Table 1) was utilised to estimate the $\mathrm{CO}_{2}$ emissions stock in the transport

Table 2

Regression equations for provincial ICEVs.

\begin{tabular}{lll}
\hline Province & Logistics Curve Equation & $\mathrm{R}^{2}$ \\
\hline Gauteng & $y=717.15 x^{2}+62604 x+999073$ & 0.99 \\
KwaZulu Natal & $y=906.33 x^{2}-4813.1 x+560580$ & 0.96 \\
Western Cape & $y=1031.8 x^{2}-4971 x+740461$ & 0.97 \\
Eastern Cape & $y=411.73 x^{2}-1948 x+252084$ & 0.96 \\
Mpumalanga & $y=264.9 x^{2}-2080.1 x+207427$ & 0.96 \\
Free State & $y=587.45 x^{2}-5091.1 x+195086$ & 0.98 \\
North West & $y=526.94 x^{2}-4784 x+127315$ & 0.98 \\
Northern Cape & $y=154.81 x^{2}-1314.8 x+68135$ & 0.97 \\
Limpopo Province & $y=243.57 x^{2}-652.98 x+181270$ & 0.94 \\
\hline
\end{tabular}

Table 3

Monthly income and proportion of households with ICEVs.

\begin{tabular}{ll}
\hline Monthly Income Category & Proportion of Households with a Motor Vehicle \\
\hline Up to R799 & $2.8 \%$ \\
R800-R1 399 & $4.5 \%$ \\
R1 400-R2 499 & $2.9 \%$ \\
R2 500-R4 999 & $9.3 \%$ \\
R5 000-R7 999 & $20.7 \%$ \\
R8 000-R10 999 & $44.7 \%$ \\
R11 000-R19 999 & $75.2 \%$ \\
R20 000 & $145.3 \%$ \\
\hline
\end{tabular}

Source: Van Heerden [39]; IRR, Eighty20, XtracT based on AMPS [40]. 
Table 4

Expenditure on Transport and Vehicle Purchases per decile.

\begin{tabular}{|c|c|c|c|c|c|c|c|c|c|c|}
\hline DECILE & 1 & 2 & 3 & 4 & 5 & 6 & 7 & 8 & 9 & 10 \\
\hline \% Transport & 11.8 & 10.7 & 10.7 & 11.3 & 11.1 & 12 & 12.9 & 13.8 & 15.1 & 19.6 \\
\hline \% Vehicle Purchase & 0 & 0 & 0 & 0.1 & 0.1 & 0.3 & 0.9 & 1.8 & 3.7 & 12 \\
\hline
\end{tabular}

Source: Ruch [41].

Table 5

Weight Fractions of Factors affecting BEV Penetration.

\begin{tabular}{ll}
\hline Variable & Weight fraction \\
\hline Retail price & 0.5218 \\
Range anxiety & 0.310 \\
Reputation effect & 0.001 \\
Charging stations & 0.168 \\
\hline
\end{tabular}

Table 6

BEV targets using E-StratBEVsim.

\begin{tabular}{ll}
\hline Scenario & Number of BEVs by 2040 \\
\hline Business-as-usual (BAU) & 0 \\
Low growth (LG) & 233,700 \\
High Growth (HG) & $2,390,000$ \\
\hline
\end{tabular}

sector, based on the substitution of ICEVs with BEVs.

Carbon Emissions(Transport Sector)

$$
\begin{aligned}
= & \text { Actual ICEVs } \times \text { Annual Distance } \\
& \times\left(\mathrm{CO}_{2} \text { per } \mathrm{km} \text { Diesel ICEV } \times\right. \text { Fraction Diesel } \\
& \left.+\mathrm{CO}_{2} \text { per } \mathrm{km} \text { Petrol ICEV } \times \text { Fraction petrol }\right)
\end{aligned}
$$

Where the $\mathrm{CO}_{2}$ emissions for diesel ICEVs are 119.6\&\#x202F;g per km [42], and 153.8\&\#x202F;g per km for petrol ICEVs [42]; and the daily average distance is $71 \& \# \times 202 F ; \mathrm{km}[21]$. Vehicle population statistics in South Africa indicate that $80 \%$ of vehicles are petrol and $20 \%$ are diesel fuelled [38]. The fractions for diesel and petrol ICEVs were therefore set at 0.2 and 0.8 respectively.

\subsubsection{Linkage to range anxiety, reputation effect, charging stations} and retail cost

First a structure of the factors affecting the BEV production cost stock (such as lower battery costs with technology improvements, lower import taxes and subsidies) was built. Value Added Tax of $14 \%$ was then added to the production cost to determine the retail price. Logarithmic equations were established to determine the lithiumion battery cost (Equation (6)) and subsidies (Equation (7)), for years which were not cited in literature and spanning the timeframe of the simulator.

Battery Cost $($ time $)=-355.4 \ln ($ time $)+935.2 ;\left(R^{2}=0.95\right)$

Subsidies $($ time $)=-105 \ln ($ time $)+25000$

Additional BEVs were added to the BEV targets causally linked to the production costs (the lower the production costs, the greater the additional sales of BEVs). This trend would have to be calibrated over time as more empirical data is obtained through various EV projects and initiatives in South Africa. For this project, the following relationship was used (Equation (8)).

\begin{tabular}{|c|c|c|c|}
\hline Scenario & BEV target & Scenario Detail & Purpose of Scenario \\
\hline $\begin{array}{l}\text { Disposable } \\
\text { Income and } \\
\text { ICEV } \\
\text { affordability }\end{array}$ & $\begin{array}{l}\text { Business- } \\
\text { as-usual }\end{array}$ & $\begin{array}{l}\text { Actual vs Affordable ICEVs } \\
\text { Per Income Decile } \\
\text { nationally }\end{array}$ & $\begin{array}{l}\text { To determine the } \\
\text { difference in the ICEV } \\
\text { based on disposable } \\
\text { income and the actual } \\
\text { number registered per } \\
\text { province. } \\
\text { Provides information } \\
\text { on which income } \\
\text { groups purchase more } \\
\text { vehicles than they can } \\
\text { afford. }\end{array}$ \\
\hline $\begin{array}{l}\text { Carbon } \\
\text { Emissions }\end{array}$ & $\begin{array}{l}\text { - Business- } \\
\text { as-usual } \\
\text { - } \text { Low } \\
\text { growth } \\
\text { - High } \\
\text { Growth }\end{array}$ & $\begin{array}{l}\text { National and provincial } \\
\text { reduction in } \mathrm{CO}_{2} \\
\text { Emissions in the transport } \\
\text { industry and increase in } \\
\mathrm{CO}_{2} \text { Emissions due coal } \\
\text { power generation }\end{array}$ & $\begin{array}{l}\text { Comparison of } \mathrm{CO}_{2} \\
\text { emissions for the } \\
\text { different BEV targets } \\
\text { to determine how } \\
\text { significant BEV } \\
\text { technology } \\
\text { contribution is } \\
\text { towards } \\
\text { environmental targets } \\
\text { nationally and per } \\
\text { province (calculated as } \\
\text { a percentage change } \\
\text { from the Business-as- } \\
\text { usual target). }\end{array}$ \\
\hline $\begin{array}{l}\text { Electricity } \\
\text { Demand }\end{array}$ & $\begin{array}{l}\text { - Low } \\
\text { Growth } \\
\text { - High } \\
\text { Growth }\end{array}$ & $\begin{array}{l}\text { Change in BEV demand } \\
\text { due to reduction in retail } \\
\text { price and decrease in } \\
\text { range anxiety (nationally). }\end{array}$ & $\begin{array}{l}\text { Indicates which } \\
\text { province will require } \\
\text { more electricity for } \\
\text { charging based on BEV } \\
\text { targets, will allow for } \\
\text { insights into regional } \\
\text { planning for BEV } \\
\text { charging } \\
\text { infrastructure. To } \\
\text { determine the driving } \\
\text { factor with the } \\
\text { greatest sensitivity to } \\
\text { increase the number of } \\
\text { BEVs and the } \\
\text { electricity demand. }\end{array}$ \\
\hline
\end{tabular}

Table 7

E-StratBEVsim scenarios.

Penetration rate of BEVs (time)

$$
=-3 E-09(\text { time }) 2+0.0012(\text { time })-11.305 ; R^{2}=0.9793
$$

"Range anxiety", 3 was also factored into the influences on BEV market penetration. According to Parker [43]; range anxiety would decrease if the range of the BEV was higher, possibly by improved battery technology allowing for higher driving ranges in the future. A ratio of range anxiety to battery range was calculated and Equation (9) was established, based on customer survey data collated in the BEV study by Langley [11].

\footnotetext{
${ }^{3}$ Driver worrying that battery of the electric vehicle will run out of power before they arrive at their destination.
} 
Range Anxiety $($ time $)=-0.001(\text { time })^{2}+0.1886($ time $)+85.035$

A model structure was developed to causally link range anxiety to the BEV penetration rate and the number of additional BEVs from this feedback relationship was added to the BEV targets. The reputation effect driver was calculated next, with the reputation improving over time with a related increase in BEVs. Similarly, a structure linking the scaled impact of charging infrastructure was built. Different weights were assigned to the different drivers: retail price, charging stations, reputation effect and range anxiety (Table 5) based on stakeholder engagements and work group discussions. These weightings can be calibrated for greater accuracy as more empirical data is obtained in the future.

\subsection{Target definition}

The timeframe for the simulator was 2015 [43] until 2050, to coincide with the timelines for the Green Transport Strategy [5], and the Integrated Energy Plan [1]. The BEV targets for E-StratBEV are listed in Table 6. The High Growth uses a target of 2.39 million EVs by 2040 based on South Africa's commitment to the Paris Agreement [5]. The Low Growth for this study uses a GDP proxy with a BEV target of 233,700 .

\subsection{Scenario definition}

The E-StratBEV scenarios were those shown in Table 7. The simulator timeframe extended from 2015 until 2050 and BEVs were introduced from 2019 until 2040.

\subsection{E-StratBEV validation}

Model validation is carried out on a structural level (assessing if the model's influence structure is consistent with that of the real system) [44], in terms of the model behaviour (determining if the model qualitatively produce the same results as the real system with respect to rates of change, oscillations, stability, etc.); empirically (checking if the model outputs correspond quantitatively (within the bounds of its purpose) with empirical results from the real system) [45]; and in terms of the application (determining if the modelled domain, complexity and functionality aligned with the purpose of the simulation) [46].

Validation of the structure and key variables in E-StratBEV was through frequent internal and external stakeholder engagements to ensure that there was consistency in drivers and dynamics through expert opinion. Parameterization of time series data, in instances where there was insufficient empirical history or data consistency for the South African EV market, was through regression analysis. Data for the supply module and the demand module was obtained from operational planning staff at the national utility Eskom.

\section{E-StratBEV results}

\subsection{Disposable income and ICEV affordability scenario}

The scenario assumed Business-as-usual zero BEVs. The model results, shown in Fig. 2, for 2015, 2030 and 2050 show that Gauteng has the largest concentration of ICEVs and the largest difference in those years, between the Actual and Affordable ICEVs (1.75, 3.36 and 4.29 mill respectively), followed by the Western Cape with a difference between the Actual and Affordable ICEVs of 0.54 mill, 1.19 mill and 1.56 mill in 2015, 2030 and 2050, respectively. The lowest number of Actual ICEVs and difference between Actual and
Affordable ICEVs in the Northern Cape with 0.02 mill, 0.08 mill and 0.11 mill in 2015, 2030 and 2050 respectively. For all provinces, households purchase more vehicles than disposable income constraints.

On a decile level (Fig. 3), the difference between Actual and Affordable ICEVs for deciles 1,5 and 10 are 0.32, 1.58 and 3.17 million, respectively. The values increase to $0.72,3.58$ and 7.16 million ICEVs in year 2030, with an even larger gap for deciles 1,5 and 10 in 2050 (0.93, 4.64 and 9.28 mill ICEVs, respectively). The middle income group (decile 5) tends to spend more than they can afford on ICEV purchases in 2015 with the situation worsening by 2050. The lowest income group (decile 1 ) appears to remain relatively constant in spending behaviour possibly due to their reliance on public transport for commuting. The highest income group (decile 10) has the highest gap between Actual and Affordable ICEVs in 2015 with the situation almost tripling by 2050.

The results are consistent with the 2015 Gauteng City-region Observatory Quality of Life Survey [47], which showed that Gauteng is the wealthiest province in South Africa, with the middle and higher income groups having the most private vehicle purchases while public transportation retains its dominance in the lowest income groups from 2015 until 2050.

The E-StratBEV was used to compare the difference in the BEV provincial distributions for the Low Growth and High Growth scenarios based on spending behaviour of the population within the various income groups. If BEVs purchases align with the current practices on vehicle expenditure within deciles then the expected BEV distributions per province is lower than the expected targets. This means that nationally, although the Low Growth scenario indicates about 233,700 BEVs by 2040 , an adjusted estimation based on the spending behaviour within deciles, results in 44,155 BEVs, while the High Growth scenario could have an adjustment down to 451,736 BEVs from the expected target of 2.39 million BEVs in 2040.

\subsection{Carbon emissions}

Fig. 4 shows the relative change in carbon emissions from the Business-as-usual no BEV target to the Low Growth (BEV\&\#x202F;=\&\#x202F;233,700) and High Growth (BEV\&\#x202F;=\&\#x202F;2.39 million) targets, after substitution with ICEVs cumulative from 2019 until 2040. The $\mathrm{CO}_{2}$ emissions in the electricity sector (residential only) refers to the emissions generated from coal-fired power stations due to additional electrical energy consumption by the BEVs due to charging. This is compared to the decrease in $\mathrm{CO}_{2}$ emissions in the transport sector (for the passenger vehicle category and then all vehicle categories) due to BEV substitution of ICEVs.

The results indicate a negligible net overall impact on $\mathrm{CO}_{2}$ emissions for the Low Growth BEV target with an increase of $0.24 \%$ $\mathrm{CO}_{2}$ emissions in the electricity sector compared to the $0.48 \%$ decrease in $\mathrm{CO}_{2}$ emissions in the transport sector (all vehicle categories), however, if the passenger vehicle category is exclusively considered, there is a $1.1 \%$ decrease in $\mathrm{CO}_{2}$ emissions in the transport sector. The High Growth target results in $2.47 \%$ increase in $\mathrm{CO}_{2}$ emissions in the electricity sector and a $4.92 \%$ decrease in $\mathrm{CO}_{2}$ emissions in the transport sector (all vehicle categories) or $11.24 \%$ decrease if the passenger vehicle category is only considered. The High Growth BEV target clearly shows that the substitution of BEVs with ICEVs may reduce the transport sector emissions but the net impact on environmental emissions is not resolved.

Fig. 5 illustrates the change in cumulative $\mathrm{CO}_{2}$ emissions in each of the provinces for a High Growth BEV target of 2.39 million from 2019 until 2040, in the transport and electricity sectors. These calculations are based on the premise that the current energy mix remains coal heavy. In terms of $\mathrm{CO}_{2}$ emissions reduction in the 


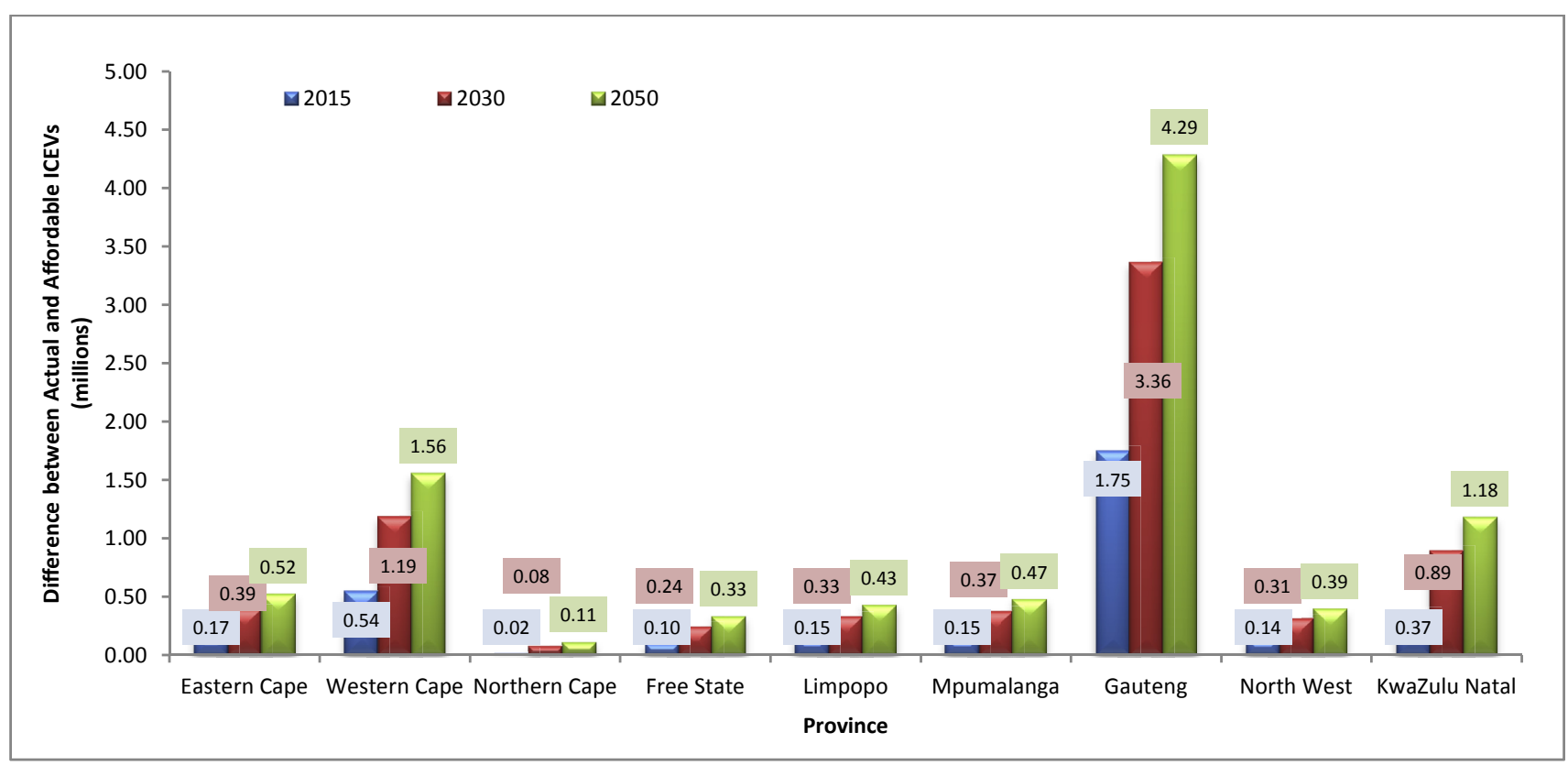

Fig. 2. ICE Vehicles (Affordable vs Actual) per Province.

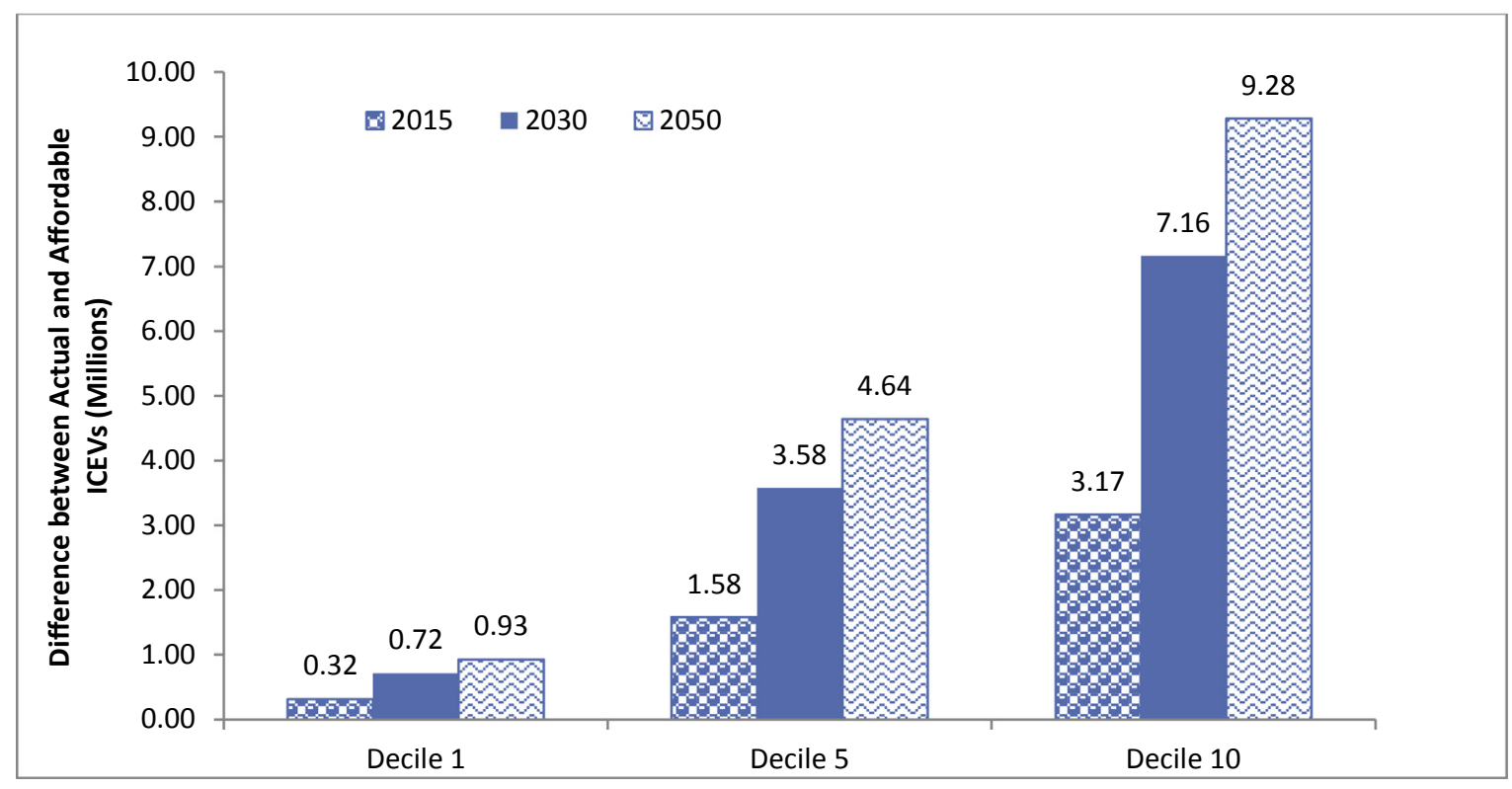

Fig. 3. Difference between actual and affordable ICEVs in 2015, 2030 and 2050.

transport sector only, Gauteng experiences the largest benefit (35.51 Mton decrease), followed by the Western Cape (14.76 Mton decrease) and then KwaZulu Natal (11.64 Mton decrease). The KwaZulu Natal province has the highest net benefit in carbon emissions (decrease in the transport sector and an increase in the energy sector).

The results presented in Section 4.1 indicate that consumers in the Northern Cape and the Free State provinces are far more likely to purchase vehicles within their disposable income constraints, and thus the expectation for the high uptake of BEVs to impact the transport sector is low. In provinces such as Gauteng, which has the highest national GDP (R1.06 billion in 2015) [48], and is driven by finance, real estate and the business services sector [49], the substitution of ICEVs with BEVs is not a particularly effective solution to reduce the provincial environmental emissions since the net cumulative $\mathrm{CO}_{2}$ emissions in the transport and the energy sector is zero even though the province has the highest number of registered ICEVs.

\subsection{Residential electricity consumption}

The additional electricity consumption due to the Low Growth and High Growth BEV targets in 2040 is shown in Fig. 6. Gauteng is expected to add an additional 4516\&\#x202F;GWh (High Growth) and 441\&\#x202F;GWh (Low Growth) to the province's residential consumption; followed by KwaZulu Natal with an additional 


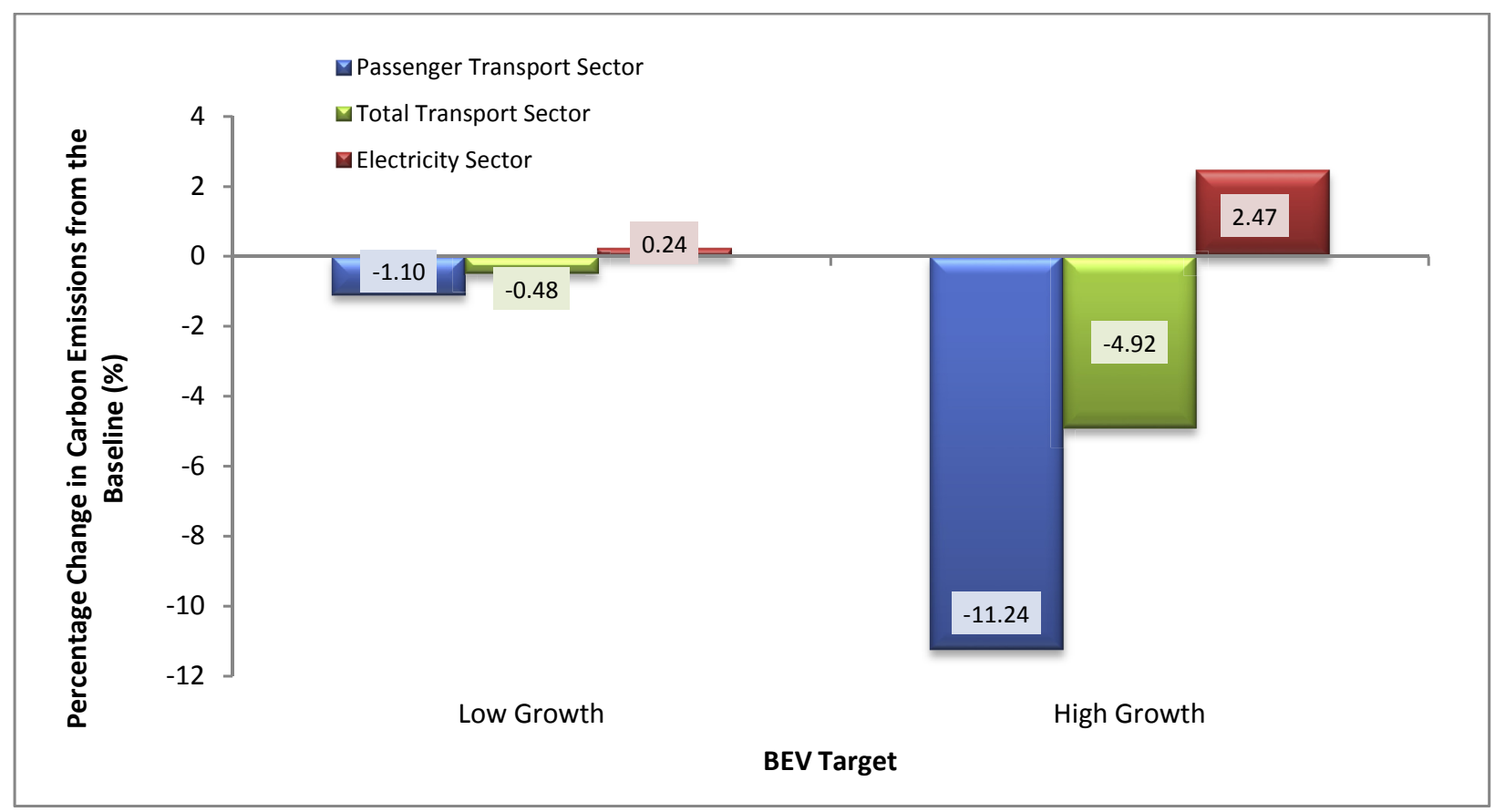

Fig. 4. Percentage change in $\mathrm{CO}_{2}$ emissions for the low growth and high growth scenarios (2019-2040).

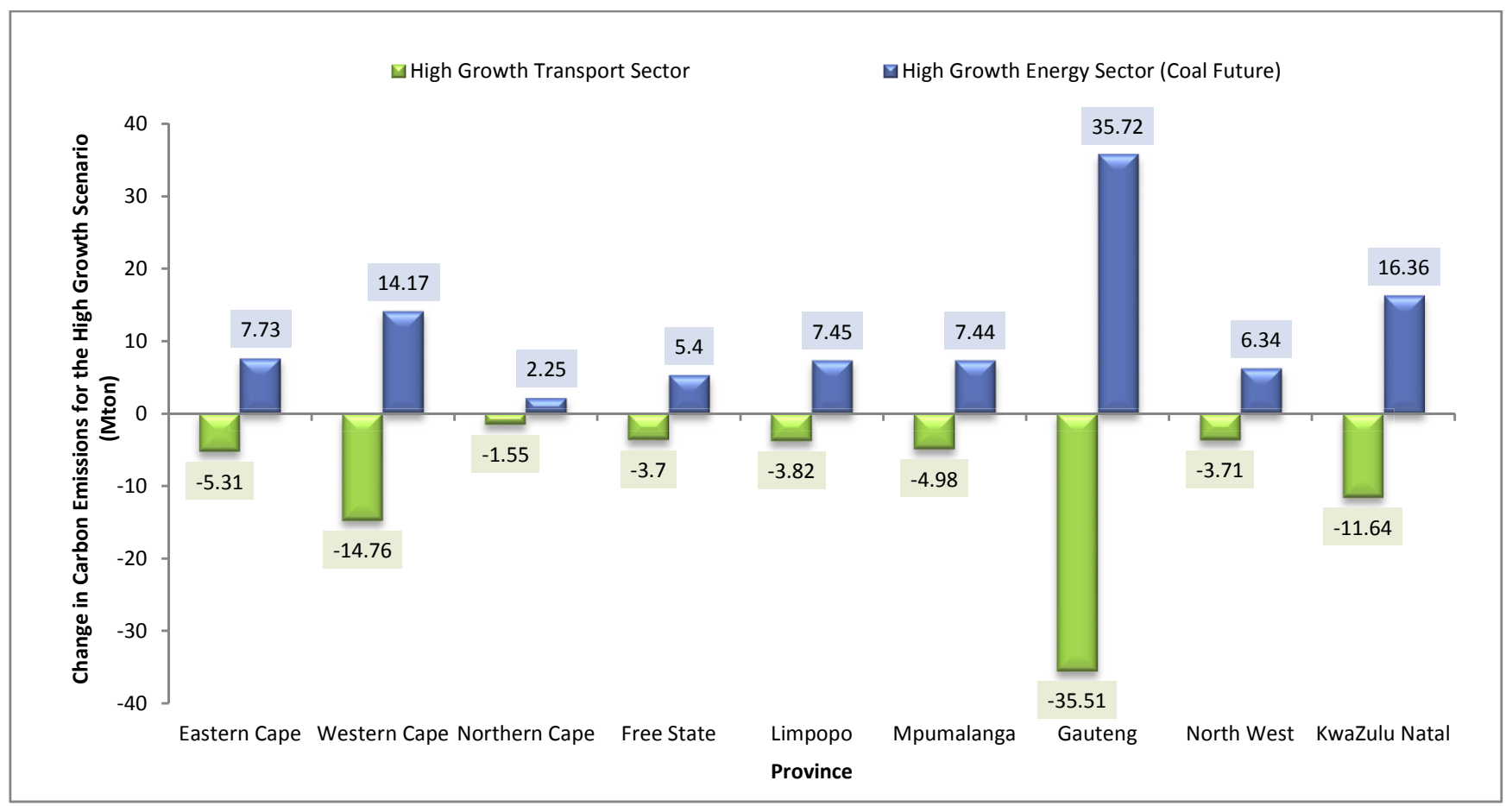

Fig. 5. Percentage Change in Provincial $\mathrm{CO}_{2}$ Emissions (BEV Substitution\&\#x202F; $=\& \# x 202 \mathrm{~F} ; 2.39$ million).

2072\&\#x202F;GWh for the High Growth and 175\&\#x202F;GWh for the Low Growth. The impact of BEVs on the residential electricity consumption is the lowest in the Northern Cape and Free State provinces.

Fig. 7 shows the additional number of BEVs due to various drivers: decrease in retail price (including the impact of battery cost reduction on the overall production cost), a $50 \%$ reduction in import taxes $(42 \%-21 \%)$ and in range anxiety, an increase in charging stations and in the reputation of BEVs. Results from the E-StratBEV show that the decrease in BEV purchase price, to bring it on par with its ICEV counterpart, results in the largest number of additional BEVs (944 for the Low Growth scenario and an additional 9658 BEVs for the High Growth scenario). A comparable number of additional driver influenced BEVs enter the system when increasing charging stations and improving range anxiety. A consumer's risk tolerance for new technology is influenced by public 


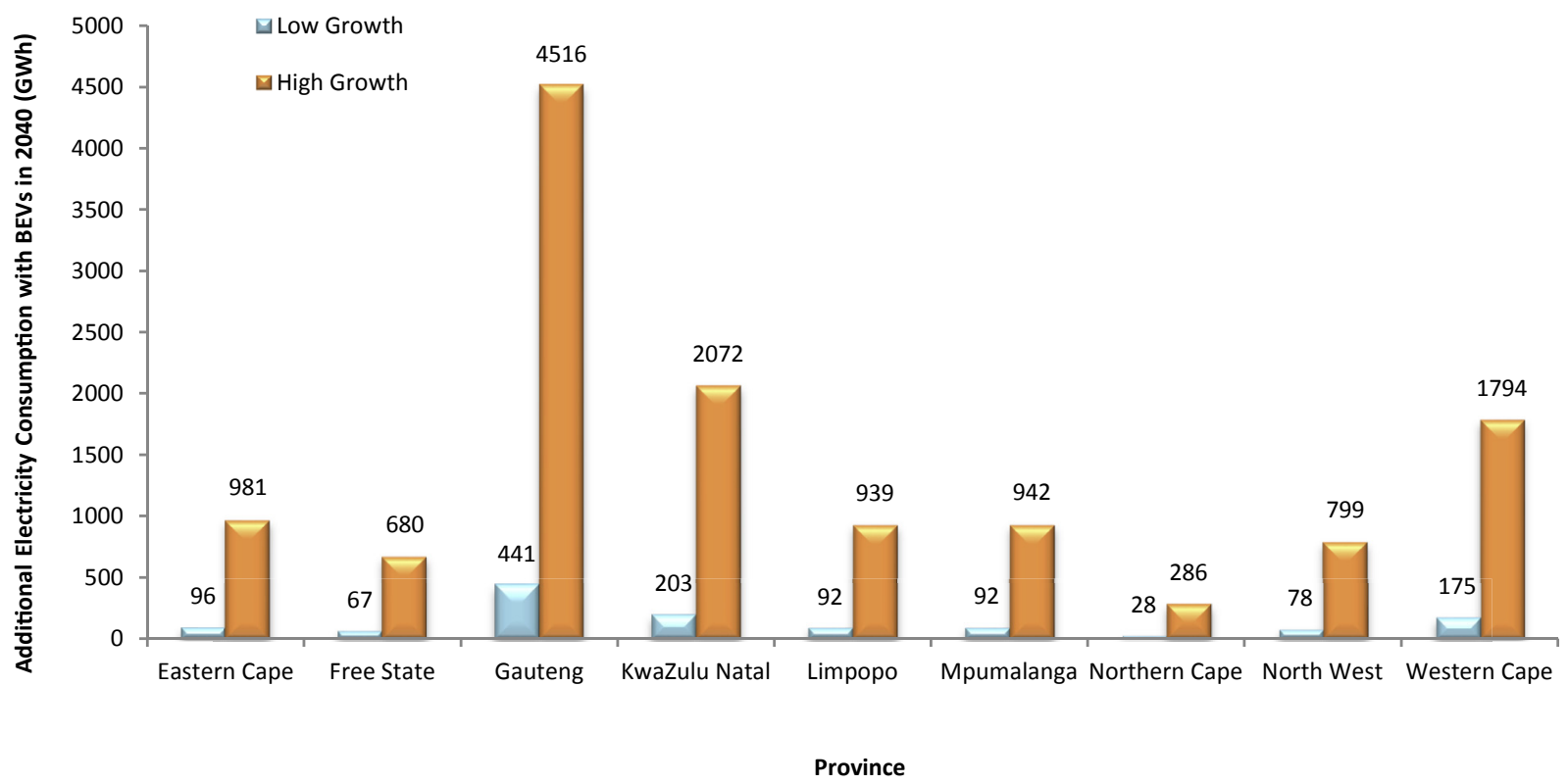

Fig. 6. Provincial BEV electricity consumption in 2040.

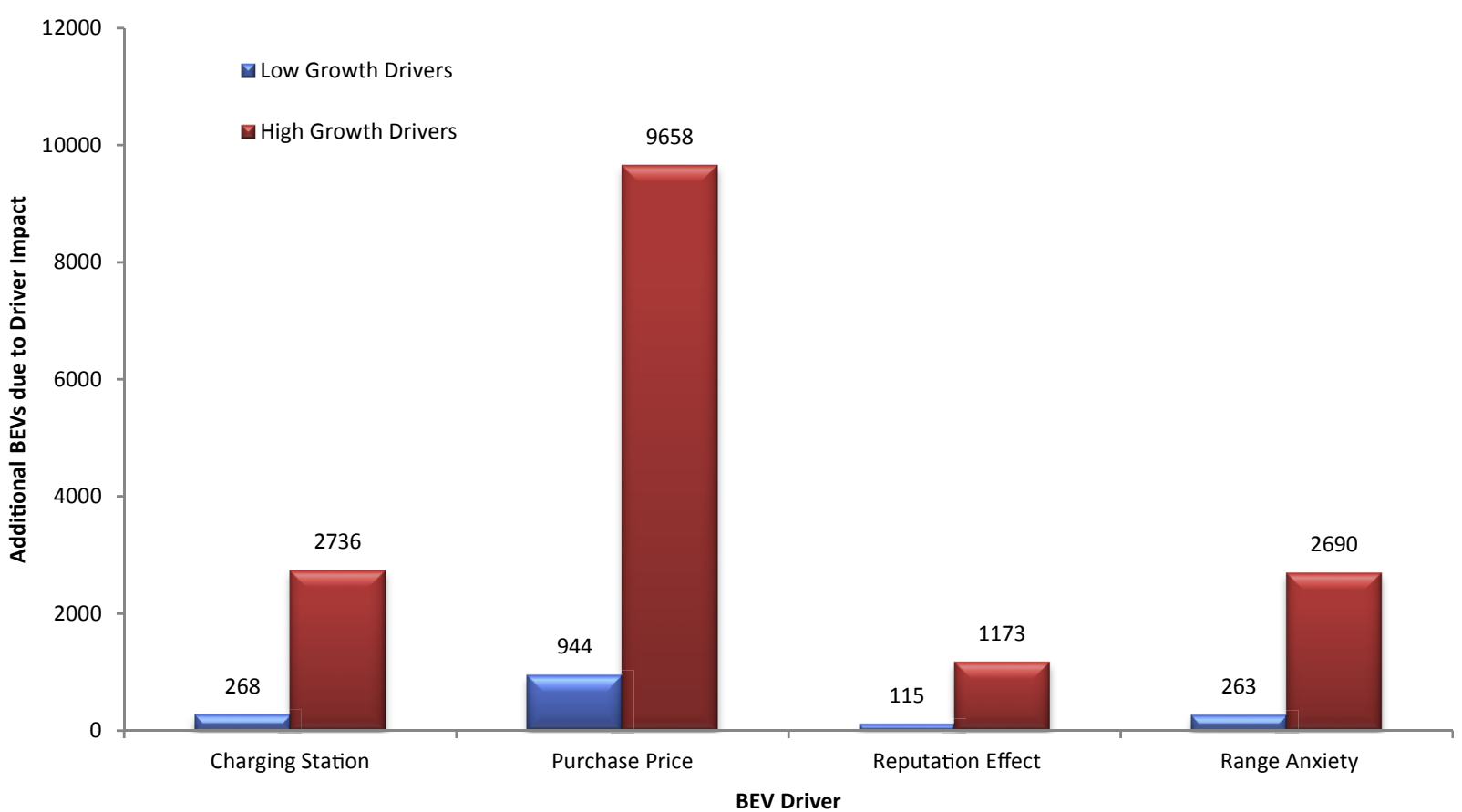

Fig. 7. Additional cumulative electricity consumption due to BEV drivers (2019-2050).

attitudes and preferences, thus the reputation of BEVs is an important consideration which will introduce an additional number of BEVs, although not as dominant as the other driver impacts [6].

The E-StratBEV model was developed to understand the relationship between disposable income and BEV affordability on a provincial level from 2019 to 2040 . The scenarios included looking at the difference between the Actual registered ICEVs and the Affordable ICEVs based on disposable income; the comparison of $\mathrm{CO}_{2}$ emission reduction in the transport industry and $\mathrm{CO}_{2}$ emission increase in the energy sector due coal power generation (with increased BEV charging requirements); and the impact on provincial residential demand due to BEVs.

The results indicate that the Gauteng, Western Cape and Kwazulu-Natal provinces have households which purchase more vehicles than what is expected based on their disposable income. On a national income decile level, deciles 5 and 10 have households' which purchase far more vehicles than what would be expected based on disposable income constraints. The lowest difference between Actual and Affordable ICEVs was for the Northern Cape and the Free State. This means that energy plans should incorporate these expectations and BEV infrastructure may have to be 
established in these regions to accommodate the higher relative substitution of BEVs with ICEVs. The high difference between Actual and Affordable ICEVs in deciles 5 and 10 could be attributed to possible vehicle finance schemes, with high balloon payments and interest rates, which may encourage consumers to live on credit. Further, other factors which may explain the variance could be competition for material welfare or for status in urban areas, where consumers fulfil desires as opposed to needs, may result in purchases of vehicle purchases they cannot afford, resulting in high debt.

Based on the calculations, it is likely that in the Northern Cape and the Western Cape provinces, BEVs could be included as part of the technological drive to reduce the environmental transport emissions, compared to the other provinces. However, based on the declining employment in their agriculturally dominated economies, even if BEVs could assist in decreasing transport emissions, affordability based on disposable income becomes a key determinant. Provinces such as Gauteng may not be able to leverage on BEV substitution of ICEVs to significantly reduce provincial environmental emissions because of the negligible net impact in the energy and transport sectors. Clearly other initiatives need to be carried out to reduce the $\mathrm{CO}_{2}$ emissions besides the promotion of sustainable transport, such as: (i) introducing environmentally friendly and fuel efficient aircraft [50]; (ii) launching more energy efficient drives such as LED lighting, energy efficient appliances, effective home and water heating etc. [51]; (iii) less waste and consumption of water and an increase in recycling [52]; and (iv) continuation of climate change research and initiatives towards a clean sustainable economy [53].

In terms of the drivers impacting the rate at which BEVs may enter the market; decreased purchase price, followed by a reduction in charging infrastructure and range anxiety (through improved battery technology with higher driving ranges), would have the biggest impact on BEV sales, thus increasing the residential electricity consumption.

The limitations of the study is that, although it allowed for an understanding of patterns of behaviour over time for various scenarios, the accuracy of estimations depended on empirical data, which was not consistent and logical for use for some model structures, such as the predicted decrease in Li-ion batteries [54] and production costs of BEVs [55].

\section{Conclusions}

The E-StratBEV model was developed to understand the relationship between disposable income and BEV affordability on a provincial level, together with influences such as range anxiety and overall retail price for a simulation time period of 2015-2050. The scenarios included looking at the difference between the actual registered ICEVs and the affordable ICEVs based on disposable income; the comparison of $\mathrm{CO}_{2}$ emissions in the transport industry and due coal power generation (with increased BEV charging requirements); and the impact on provincial residential demand due to BEVs.

The results indicate that the Gauteng, Western Cape and Kwazulu-Natal provinces have households which purchase more vehicles than what is expected based on their disposable income. On a national income decile level, deciles 5 and 10 have households' which purchase far more vehicles than what would be expected based on disposable income constraints. The lowest difference between actual registered ICEVs and affordable ICEVs was for the Northern Cape and the Free State. This means that energy plans should incorporate these expectations and BEV infrastructure may have to be established in these regions to accommodate the higher relative substitution of BEVs with ICEVs. The high difference between Actual and Affordable ICEVs in decile 5 could be attributed to possible vehicle finance schemes, with high balloon payments and interest rates, which may encourage consumers to live on credit. Further, other factors which may explain the variance could be competition for material welfare or for status in urban areas, where consumers fulfil desires as opposed to needs, may result in purchases of vehicle purchases they cannot afford, resulting in high debt. The gap in decile 10 would not be explained by affordability based on disposable income, since this income group also leverages returns from investments to purchase vehicles, not reflected in the disposable income.

Based on the calculations, it is likely that in the Northern Cape and the Free State provinces, BEVs would be an effective technological drive to reduce the environmental transport emissions, compared to the other provinces. However, based on the declining employment in their agriculturally dominated economies, even if BEVs could assist in decreasing transport emissions, affordability based on disposable income becomes a key determinant. Provinces such as Gauteng may not be able to leverage on BEV substitution of ICEVs to significantly reduce provincial environmental emissions because of the small relative impact.

In terms of the drivers impacting the rate at which BEVs may enter the market (battery cost, range anxiety, and import taxes); reducing range anxiety (through improved battery technology with higher driving ranges), will have the biggest impact on BEV sales.

The limitations of the study is that, although it allowed for an understanding of patterns of behaviour over time for various scenarios, the accuracy of estimations depended on empirical data, which was not consistent and logical for use for some model structures, such as the predicted decrease in Li-ion batteries [54] and production costs of BEVs [55].

An expansion of the scope of this study could include drivers affecting the price and quality of oil and thus expected efficiency improvements in diesel and petrol and reduction of $\mathrm{CO}_{2}$ emissions in ICE vehicles. Carbon emissions estimates assumed that South Africa would rely on coal-fired electricity generation, to meet the additional electricity requirements. Future studies can consider the potential of renewable electricity in meeting the additional demand. The degradation of BEV batteries and changes in fuel efficiency over time was excluded. The study only looked at tank-towheel emissions for passenger vehicles in the residential sector, however, the impact on electricity demand could be markedly more if other vehicle categories such as buses and trucks become electrified and/or if the average daily distances increase.

\section{Funding}

The research effort was made possible with the financial support of Eskom Holdings SOC Ltd

\section{Acknowledgement}

The author would like to thank Eskom SOC, Research Testing \& Development for permission to make use of data and to provide technical reviews on the project progress; as well as Danie Booyens for support on model validation.

\section{References}

[1] DOE. (2016, November 22). Integrated energy plan (IEP). Retrieved January 19 2018, from Department of Energy: http://www.energy.gov.za/files/IEP/ presentations/Integrated-Energy-Plan-22-Nov-2016.pdf

[2] Eskom. (2010, February). Electricity generation. Retrieved January 18, 2018 from Eskom: http://www.eskom.co.za/Whatweredoing/ElectricityGeneration/ Pages/Electricity_Generation.aspx

[3] Merven, B., Stone, A., Hughes, A., \& Cohen, B. (2012). Quantifying the energy 
needs of the transport sector in South Africa: a bottom-up model. Energy Research Centre. Cape Town: University of Cape Town.

[4] Seymore R, Inglesi-Lotz R, Blignaut J. June). A greenhouse gas emissions inventory for South Africa: a comparative analysis. Renew Sustain Energy Rev 2014;34:371-9.

[5] DOT. (2016, August). Draft green transport Strategy: (2017-2050). Retrieved January 17, 2018, from Chemical \& Allied Industries Association: https:// www.caia.co.za/wp-content/uploads/2016/08/Draft\%20GTS\%20Revised\%20v5. pdf

[6] September) Egbue O, Long S. Barriers to widespread adoption of electric vehicles: an analysis of consumer attitudes and perceptions. Energy Pol 2012;48:717-29.

[7] Zubaryeva A, Thiel C, Barbone E, Mercier A. November). Assessing factors for the identification of potential lead markets for electrified vehicles in Europe: expert opinion elicitation. Technol Forecast Soc Change 2012;79(9):1622-37.

[8] April) Venter CJ, Mohammed SO. Estimating car ownership and transpor energy consumption: a disaggregate study in Nelson Mandela Bay. J S Afr Inst Civ Eng 2013;55(1).

[9] July) OECD. Economic surveys: South Africa 2017. Paris: OECD Publishing; 2017.

[10] Suleman M, Gaylard M, Tshaka S, Snyman C. South African cities green transport programme: accelerating the transition to green transport. SANEDI, SA cities network, linkd, department of environmental Affairs. Midrand, South Africa: SA Green Fund, Development Bank of SA; 2015.

[11] Langley, P. (2016). reportElectric vehicle results. Report 1789591. Johannesburg, South Africa: Eskom Research Testing and Development

[12] GIZ. (2015, October 31). reportProgress report sustainability 2015. Retrieved March 16, 2018, from GIZ: https://www.giz.de/en/downloads/giz2015-enprogress-report-sustainability.pdf

[13] Reyneke M, Sorokáčová A, Pitt L. Managing brands in times of economic downturn: how do luxury brands fare? J Brand Manag 2012;19(6):457-66.

[14] Randall, T. (2016, February 25). Here's how electric cars will cause the next oil crisis. Bloomberg New Energy Finance [Online] https://www.bloomberg.com/ features/2016-ev-oil-crisis/. [2018, June 12].

[15] Sullivan J, Salmeen I, Simon C. PHEV marketplace penetration: an agent based simulation. Working Paper of the University of Michigan Research Institute; 2009.

[16] Al-Alawi B, Bradley T. Review of hybrid, plug-in hybrid, and electric vehicle market modeling studies. Renew Sustain Energy Rev 2013:190-203.

[17] Grahn, P. (2014). reportElectric vehicle charging modeling. Doctoral Thesis. Stockholm, Sweden: School of Electrical Engineering, Royal Institute of Technology.

[18] Nemry F, Brons M. Market penetration scenarios of electric drive vehicles. Plug-in hybrid and battery electric vehicles.. Luxembourg: Publications Office of the European Union; 2010.

[19] September) Stadler M, Marnay C, Sharma R, Mendes G, Kloess M. Modeling electric vehicle benefits connected to smart grids. In: 7th IEEE vehicle powe and propulsion conference. Chicago; 2011.

[20] Zhang C, Qin C. Exploration of the growing trend of electric vehicles in Beijing with system dynamics method and vensim model. China: System Dynamics Society; 2014.

[21] january) Langley P. Electric vehicles research results 2014. Eskom RT\&D; 2015.

[22] Vaneman WK, Triantis K. The dynamic production axioms and system dynamic behaviors: the foundation of future integration. J Prod Anal 2003;19: 93-113.

[23] Meyer P. Bi-logistic growth. Technol Forecast Soc Change 1994;47:89-102.

[24] EPRI. Power generation technology data for integrated Resource plan of South Africa. California: Electric Power Research Institute; 2010.

[25] Makgetla, N., \& Fotoyi, A. (2016). The real economy Bulletin, provincial review 2016. Retrieved March 27, 2018, from Trade \& Industry Policy Strategies (TIPS):

$\mathrm{sa}=\mathrm{t} \& \mathrm{rct}=\mathrm{j} \& \mathrm{q}=\&$ esrc $=\mathrm{s} \&$ source $=$ web $\& \mathrm{~cd}$

$=8 \& \mathrm{cad}=$ rja\&uact $=8 \&$ ved $=0$ ahUKEwj 2 -vPllozaAhUKKsAKHTeMBul QFghfMAc\&url=http\%3A\%2F\%2Fwww.tips.org.za\%2Fmanufacturing-data\% 2Fthe-real-economy-bulletin\%2Fprovincial-review\%2Fitem\%2Fdownload\% 2F1515_baad

[26] Nel W. Eskom technology systems model using system dynamics feedback report 1. Johannesburg: Eskom Holdings SOC: Eskom Research Testing \& Development; 2011.

[27] Botes, E. (2014, December 15). Note on the benchmark revisions and rebasing of South Africa's national accounts statistics. Retrieved March 2018, from Reserve Bank: https://www.resbank.co.za/Lists/News\%20and\%20Publications/ Attachments/6534/05Note\%20on\%20the\%20benchmark\%20revisions\%20and\% 20rebasing\%20of\%20South\%20Africa\%27s\%20national\%20accounts\% 20statistics.pdf
[28] Van de Ven, P. (2015, February). New standards for compiling national accounts: whats the impact on GDP and other macro-economic indicators. Retrieved March 15, 2018, from OECD: http://www.oecd.org/sdd/na/newstandards-for-compiling-national-accounts-SNA2008-OECDSB20.pdf

[29] National Treasury. (2017, February 23). National Budget 2017 review. Retrieved April 10, 2018, from Treasury: http://www.treasury.gov.za/ documents/national\%20budget/2017/review/Chapter\%202.pdf

[30] DOE. (2012, October 12). A survey of energy-realted Behaviou and perceptions in South Africa: the residential sector 2012. Retrieved February 27, 2018, from Department of Energy: http://www.energy.gov.za/files/media/Pub/Survey\% 20 of\%20Energy\%20related\%20behaviour\%20and\%20perception\%20in\%20SA\% 20-\%20Residential\%20Sector\%20-\%202012.pdf

[31] July 6) Black A, Mitchell S. Policy in the South African motor industry: goals, incentives and outcomes. S Afr J Econ 2005;70(8):1273-9.

[32] Smit PC, Dams DJ, Mostert JW, Oosthuizen AG, Van der Vyver TC, Van Gass W. Economics: a South African perspective. first ed. South Africa: Juta and Company (Pty) Ltd; 1996.

[33] Dargay J, Gately D. Vehicle Ownership to 2015: implicationsfor energy use and emissions. Energy Pol 1997;25(14-15):1121-7.

[34] February) Guerra E. The geography of car ownership in Mexico City: a joint model of households' residential location and car ownership decisions. J Transport Geogr 2015;43:171-80.

[35] Collins. (2018). Definition of disposable income. (HarperCollins Publishers) Retrieved March 27, 2018, from Collins English Dictionary: https://www. collinsdictionary.com/dictionary/english/disposable-income

[36] Treasury. (2016, March). Estimates of provincial revenue and expenditure 2015/16. Retrieved March 27, 2018, from Treasury: http://www.treasury.gov. za/documents/provincial\%20budget/2015/4.\%20Estimates\%20of\%20Prov\% 20Rev\%20and\%20Exp/NW/1.\%20Budget\%200verview/NW\%20-\%20EPRE\%20-\% 20Budget\%200verview.pdf

[37] March) Manamela M, Mabaso K, Ligudu L. Gross domestic product fourth quarter 2016. Statistical release P0441. South Africa: Stats SA; 2017.

[38] ArriveAlive. (2017). Registered vehicles. Retrieved October 30, 2017, from Arrive Alive: https://www.arrivealive.co.za/Registered-Vehicles

[39] Van Heerden G. Assets \& inome 2016. IRR; 2016.

[40] AMPS. (2014, October). South Africa - all media and products survey 2014. Retrieved February 18, 2018, from DataFirst UCT: https://www.datafirst.uct. ac.za/dataportal/index.php/catalog/626

[41] Ruch W. StatsSA - P03102014 living conditions of households in South Africa 2014/15. Pretoria: StatsSA; 2017.

[42] Snyman, C. (2017, December). Electrifying mobility. (S. A. Institute, Ed.) Retrieved January 26, 2018, from EE Publishers: http://www.ee.co.za/wpcontent/uploads/2017/12/Carel-Snyman-SANEDI-Electrifying-mobility.pdf

[43] August) Parker C. Assessing the Viability of e-Mobility: assessing the Viability of e-Mobility. Johannesburg: Frost \& Sullivan; 2017.

[44] Qudrat-Ullah H. Structural validation of system dynamics and agent-based simulation models. In: Proceedings of the 19th European conference on modelling and simulation. Latvia. ECMS; 2005.

[45] Winter) Sterman JD. Appropriate summary statistics for evaluating the historical fit of system dynamics models. Dynamics 1984;10(2):51-66.

[46] Barlas Y. Formal aspects of model validity and validation in system dynamics. Syst Dynam Rev 1996;12(3):183-210.

[47] Joseph, K. (2017, May 02). Quality of Life survey 2015. Retrieved February 28, 2018, from The Gauteng City-Region Observatory: http:/www.gcro.ac.za/ media/redactor_files/GCRO_QoL_2015_Press_pack_low_res.pdf

[48] StatsSA. (2017, January). Living conditions survey 2014/15 P0310. Retrieved March 27, 2018, from Stats SA: http://www.statssa.gov.za/publications/ P0310/P03102014.pdf

[49] South Africa's Economic Structure. (2015). Retrieved December 12, 2017, from South African Mi: https://www.southafricanmi.com/south-africas-economicstructure.html

[50] September 22) Lee J, Mo J. Analysis of technological innovation and environmental performance improvement in Aviation sector. Int J Environ Res Publ Health 2011;8(9):3777-95.

[51] Herring H, Roy R. Technological innovation, energy efficient design and the rebound effect. Technovation 2007:27(4):194-203.

[52] August 31 Smith R. The environmental sustainability of paper. Graduate Stud J Organ Dynam 2011;1(1).

[53] Locatelli B, Aldunce P, Fallot A, Le Coq J-F, Sabourin E, Tapasco J. Research on climate change policies and rural development in Latin America: scope and gaps. Sustainability 2017;9(10):1831.

[54] April) Coffman M, Bernstein P, Wee S. Factors affecting EV adoption: a literature review and EV forecast for Hawaii. Florida: University of Central Florida; 2015.

[55] January) Grant A. Plug-in hybrid and battery electric vehicles in South Africa: market forecasts. Cape Town, South Africa: University of Cape Town; 2014. 